\title{
Efficiency of Magnetic Field Treatment on Pressure Sores in Bedridden Patients
}

\author{
Ferda Özdemir ${ }^{1}$, Meliha Kasapoğlu², Figen Oymak ${ }^{3}$, Sadiye Murat ${ }^{4}$ \\ 'Department of Physical Medicine and Rehabilitation, Faculty of Medicine, Trakya University, Edirne, Turkey \\ ${ }^{2}$ Department of Physical Medicine and Rehabilitation, Medical Park Hospital, Bursa, Turkey \\ ${ }^{3}$ Department of Physical Medicine and Rehabilitation, Faculty of Medicine, Trakya University, Edirne, Turkey \\ ${ }^{4}$ Department of Physical Medicine and Rehabilitation, Şanlıurfa Research and Training Hospital, Şanlıurfa, Turkey
}

\section{ABSTRACT}

Objective: Pressure sores are an important source of complications in patients who are immobilized and bedridden. We aimed to investigate the efficiency of magnetic field treatment in pressure sores.

Material and Methods: This was a randomized, double blind controlled design study. 20 patients in the study group received magneto-therapy, once a day for 30 minutes and with 150G, keeping to the BTL09 magnetotherapy device's program. In the control group, 20 patients received the dressing only once a day. The surface areas of the pressure sores were evaluated at the onset of the treatment ( $1^{\text {st }}$ day), and on the $7^{\text {th }}$ and $15^{\text {th }}$ days.

Results: When within group comparisons were conducted, a significant difference was observed between the $1^{\text {st }}$ and $7^{\text {th }}$ day, $7^{\text {th }}$ and $15^{\text {th }}$ day, and $1^{\text {st }}$ and $15^{\text {th }}$ day measures in both the groups in terms of the scar area. The average healing time for the treatment group was $10.80 \pm 4.06$ (6-20) days, and the average healing time for the control group was $18.85 \pm 9.75(5-32)$ days. There was a statistically significant difference between the two groups $(z=-2.114$ $p=0.034)$. Also, there was a significant difference in the scar area between the two groups in the $15^{\text {th }}$ day measure $(z=-3.818, p=0.000)$.

Conclusion: The healing process of the tissue can be accelerated.with the use of magnetotherapy in the treatment of pressure sores of stage II and III, Key Words: Magnetic field treatment, pressure sore, bedridden patients, scar area, healing time

\section{Introduction}

Pressure sores are an important source of complications in patients who are immobilized and bedridden. The care of these sores is difficult and expensive and they play a role in the increase of morbidity and mortality rates (1). The incidence of pressure sores among inpatients varies between 2.7-2.9\%, and the prevalence varies between 3.5-69\%. However, the risk for development of pressure sores in intensive care unit patients is higher than in other patients (incidence: $33 \%$, prevalence: $41 \%)(2,3)$.

The treatment of pressure sores is based on eliminating the contributing factors and increasing the general well-being of the patient, decreasing the pressure applied on the sore, removing the debridement of the necrotized tissue and keeping the patient clean, and disinfecting and stimulating the granulation tissue (2). We used the National Pressure Sore Advisory Panel Consensus of Development Conference in 1989 in staging the ulcers.

It is well known that some physical treatment agents have an impact in reducing healing time and improving the quality of scar tissue (3). The magnetic field, which is one of these agents, is an electrical current passing through a conductive framework (4). In the application of pulse electro-magnetic field, it has been observed that there is lysosome, ribosome and mitochondrial stimulation, and a positive change in the enzymatic activities and synthesis (4-6). Furthermore, it has also been established that the autonomous nervous system is affected and, due to this impact, vasodilatation and healing of tissue perfusion takes place as a result of increased flexibility of erythrocytes $(5,7,8)$. The additional results of this are removal of the metabolic residues from the tissues and an increase in the partial oxygen pressure $(7,9)$. There are studies showing that pulse electro-magnetic field application to large body areas increases the respiratory volume and pulse, changes the $\mathrm{pH}$ value of the blood, stimulates the macrophage, and causes anti-inflammatory, analgesic and even antiseptic and antimicrobial changes through the increase of the enzyme amounts and activities $(6,7,10)$.

Magnetic stimulation is relatively painless, has positive effects on the deep rooted neural structures, and there is no need for direct stimulator-skin contact during its application. However, the target tissue needs to be positioned within the magnetic field, and the current flow on the tissue is in the opposite direction to the current flow from the coil (2-4). The amplitude of this flow is intense under the sides of the coil. 
Also, as the static magnetic field does not create a depolarization on the neural tissue, the magnetic field needs to be pulsatile or variable $(8,9)$.

There are no conclusive programs in the area of magnetic field treatment. However, we know that, given the presence of inflammation, lower frequency and magnitude of magnetic field applications are more efficient (4).

The present study aims to investigate the efficiency of magnetic field treatment in pressure sores.

\section{Materials and Method}

The present study is devised as a randomized design. Local ethic committee approval was obtained for the study. The cases were randomized on the basis of their admission dates on computer generated codes. 45 patients were enrolled to the study. 3 patients in the magneto-therapy group and 2 patients in the control group dropped out. 3 patients did not adapt to the treatment and 2 patients did not come for control. The study was completed with a total of 40 patients, consisting of 20 patients treated with magneto-therapy and 20 control patients. The rehabilitation nurse applied the treatment and the evaluation was conducted by the physiatrist The physiatrist was blind to the treatment.

\section{Study group}

The study included patients hospitalized in the Physical Medicine and Rehabilitation, Neurology, Plastic and Reconstructive Surgery Clinics, with pressure sores due to immobilization as a result of hemiplegic, paraplegic, other neurological disorders, and amputation operations. All the pressure sores were at stage II or III. Pressure sores that were borderline to surgery and stage IV were excluded from the study. Similarly, infected sores were also excluded.

All patients were provided with flamboyant beds and it was ensured that they were repositioned at regular two hour intervals. The patients were informed about the importance of smoothing out the wrinkles in the sheets, hygiene and dryness.

Prior to the initiation of the study, the pressure sores of patients in both groups were cleansed using $0.9 \% \mathrm{NaCl}$ (isotonic solution: physiological saline). Posterior to the treatment, a closed dressing using the topical antibacterial agent mupiracine with a $2 \%$ pomade (Bactroban pomade) was applied to the sore area.

\section{Magnetic field treatment}

Patients in the study group received magneto-therapy, keeping to the BTL09 magnetotherapy (Czech Republic, 3/00) device program, once a day for 30 minutes and with $150 \mathrm{G}$.

The device used for the treatment of the first group, was the BTL09 Magnetotherapy device in our clinic. Based on the references of the magnetotherapy device, the magnetic field treatment was applied on a daily basis for 30 minutes, with a $10 * 10 \mathrm{~ms}$ pulse, at intervals of $30 \mathrm{~ms}$, and a frequency of $25 \mathrm{~Hz}$, and $9 * 5 \mathrm{~ms}$ pulse at intervals of $212 \mathrm{~ms}$ and a frequency of $4,6 \mathrm{~Hz}$ with a magnitude of $15 \mathrm{mT}$ (150G) for a duration of
15 days. It was ensured that the pressure sores remained between the solenoids and the treatment was applied from over the dressing materials.

The surface areas of the pressure sores were recorded at the onset of treatment ( $1^{\text {st }}$ day), on the $7^{\text {th }}$ and the $15^{\text {th }}$ days on transparency papers, templates were made and converted onto milimetric graphic papers. The squares inside the drawings were counted and the surface area was calculated in terms of square centimeters.

\section{Statistical analysis}

The measured variables were tested for appropriateness to a normal distribution using the Kolmogorov Smirnov test. The Mann Whitney $U$ test was used in the comparison of mean values of the two groups. Within group comparisons were conducted using a Wilcoxon sign rank test. A 0.05 level of significance was adopted.

\section{Results}

Ages of the patients included in the study varied between 39 and 89 years. The mean age of the treatment group was $66.05 \pm 12.77$ (32-89), and the mean age of the control group was $58.95 \pm 13.98$ (39-79). There was no statistically significant difference between the two groups' age distributions ( $p>0.05$ ).

The locations of the pressure sores in the treatment group were as follows: 4 (21.05\%) sacrum, 4 (21.05\%) gluteus, 2 $(10.52 \%)$ trochanter, 4 (21.05\%) heels, 6 (31.57\%) other regions. The places of the pressure sores in the control group were as follows: 4 (20\%) sacrum, 3 (15\%) gluteus, 3 (15\%) trochanter, 5 (25\%) heels, and 5 (25\%) other regions. In the treatment group, 18 were at stage II (80\%), 2 were at stage III (10\%). 12 of the pressure sores in the control group were categorized as stage II (60\%), and 8 were categorized as stage III (40\%).

No significant differences were observed between the two groups in their $1^{\text {st }}$ sizes and their $7^{\text {th }}$ day sizes $(p>0.05)$. However, there was a significant difference in their $15^{\text {th }}$ day sizes (Figure 1).

When within group comparisons were conducted, a significant difference was observed between $1^{\text {st }}$ and $7^{\text {th }}$ day, $7^{\text {th }}$ and $15^{\text {th }}$ day, and $1^{\text {st }}$ and $15^{\text {th }}$ day sizesin both of the groups in terms of the wound area (Table 1). However, it was observed that with application of MF treatment, the scar tissue showed more rapid healing. The average healing time for the treatment group was $10.80 \pm 4.06(6-20)$ days, and the average healing time for the control group was 18.85 \pm 9.75 (5-32)

Table 1. Magnetotherapy and control group scar area measurment values within group comparisons

\begin{tabular}{|lcccc|}
\hline & $\begin{array}{c}\text { Magnetotherapy } \\
\text { group }\end{array}$ & \multicolumn{2}{c|}{$\begin{array}{c}\text { Control } \\
\text { group }\end{array}$} \\
& $\mathbf{z}$ & $\mathbf{p}$ & $\mathbf{z}$ & $\mathbf{p}$ \\
\hline $1^{\text {st }} 7^{\text {th }}$ day & -3.923 & $<0.001$ & -3.969 & $<0.001$ \\
$7^{\text {th }}-15^{\text {th }}$ day & -3.301 & $<0.001$ & -3.457 & $<0.001$ \\
$1^{\text {st }}$-15 $5^{\text {th }}$ day & -3.921 & $<0.001$ & -3.930 & $<0.001$ \\
\hline Wilcoxon sign rank, ${ }^{*} \mathrm{p}<0.05$ & & & \\
\hline
\end{tabular}


days. There was a statistically significant difference between the two groups ( $z=-2.114, p=0.034)$ (Figure 2). As a result of the magnetic field application, a significant level of healing was observed in the pressure sores (Figure 3).

\section{Discussion}

Despite the fact that pressure sores are preventable lesions that should never occur, they still continue to be one of

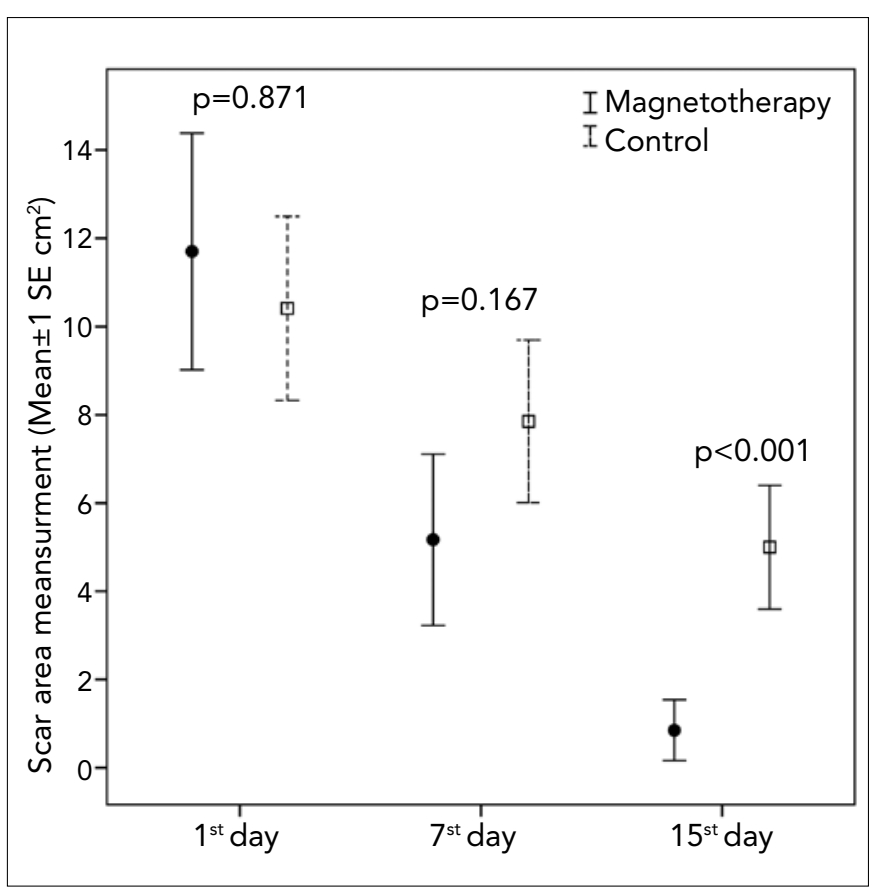

Figure 1. The mean scar area measurement of magnetotherapy and control group and comparison of the groups

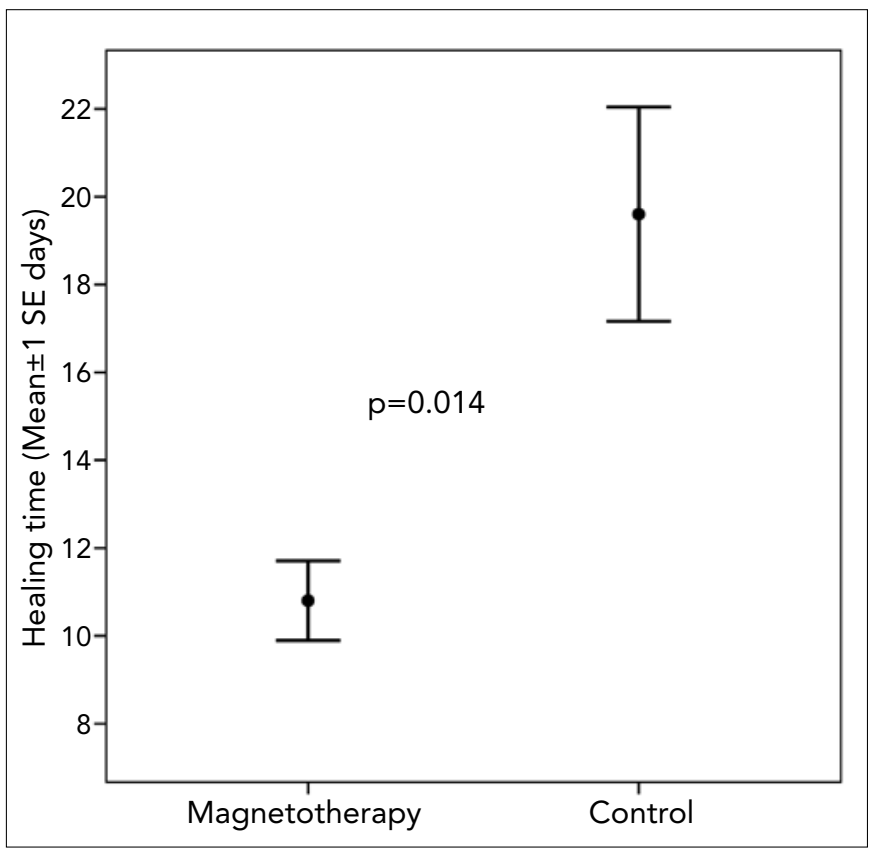

Figure 2. The average healing time in magneto-therapy and control groups the most complicated and common problems among patients with neurological or skeletal system dysfunctions. At the same time, they constitute a problem which is difficult and expensive to care for (11).

The conservative therapy for pressure sores is carried out with systemic and local wound treatment. Systemic wound treatment involves improving the general health (nutrition, anemia, spasticity...etc) of the patient (12). In local conservative treatment, various treatments such as local agents, wet-dry dressings and physical systemic agents are used. As physical treatment agents, hydro-therapy, massage, pulse ultrasound, ultraviolet, laser, electric current, cold therapy and topical hyperbaric oxygen treatment are used in the treatment of pressure sores $(2,3)$. Magnetotherapy is a treatment method which does not have direct contact with the patientand can be applied over the dressings $(4,7)$. The present study investigates the efficiency of this treatment method. The autonomous nervous system is influenced by the pulse electromagnetic field application, and, this, in return, helps the healing of tissue perfusion through the vasodilatation and increase in flexibility of erythrocytes. Magnetotherapy has anti-inflammatory, analgesic, and anti-edema effects (7-9).

The literature shows contradictory findings regarding the effects of magnetotherapy on scar healing. Flemming (13) compared the efficiency of electromagnetic treatment and standard dressing treatments in second and third degree pressure sores, and found no significant difference between the two treatment groups. Glassman et al. (14) investigated the pulse electromagnetic field treatment efficiency in the healing of soft tissue, and his findings showed no significant difference between the treatment and control groups in terms of contraction and epithelization formation. However, both authors pointed out that results may be varied by changing the PEM area wave length characteristics.

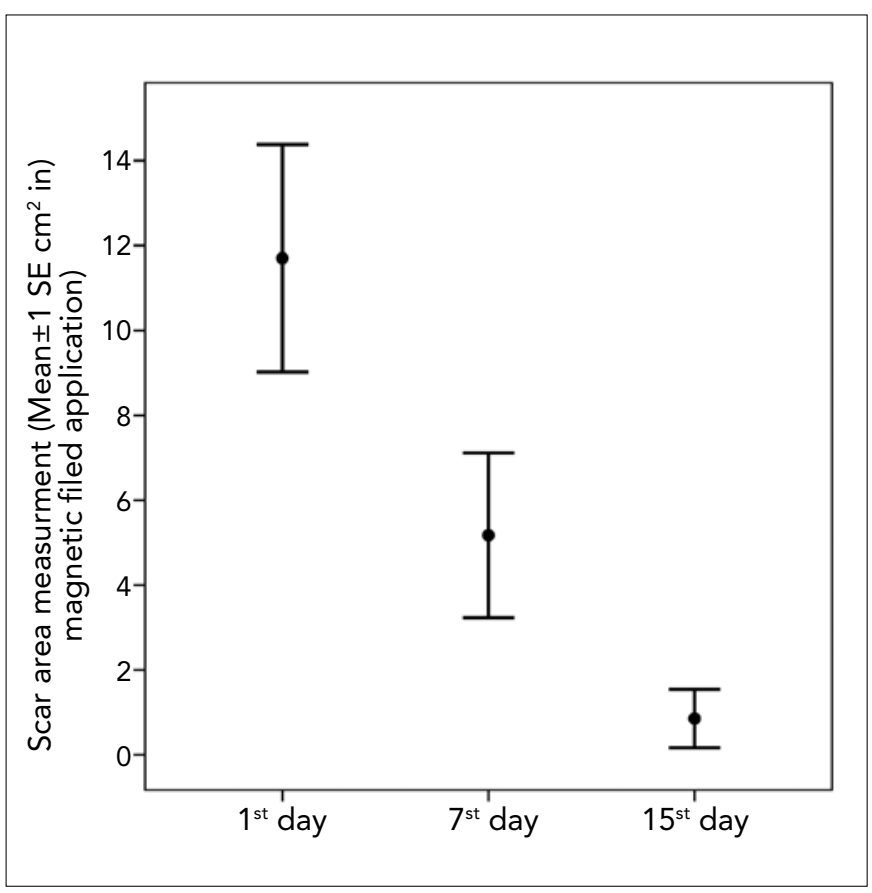

Figure 3. The effect of magneto-therapy on scar healing 
Milgram et al. (15), investigated the healing of scar tissue in rats through the use of pulse electromagnetic field treatment, and found that pulse electromagnetic field treatment does not have a significant healing impact on the scar tissue, although the use of this treatment helps the contraction and epithelization formation to take place more rapidly. The present study also shows that patients who received the magnetotherapy showed faster healing of the pressure sores.

Patino et al. (16) conducted a study investigating the effects of pulse electromagnetic treatment for cutaneous scar healing in rats, with a $20 \mathrm{mT}$ treatment of a daily dose of 35 minutes. Results showed that healing of the treatment group was statistically significantly better than the control group Lin et al. (17) investigated the effects of pulse electromagnetic field treatment in rabbits' ligament healing, conducting a histological evaluation of the treatment group, and showed that capillary and fibroblast formation and maturation takes place earlier in the treatment group.

Patino et al. (18) conducted an experimental study, examining the effects of magnetic field on the healing of scar tissue with rats. They provided a continuous (50G) treatment, and a pulse electromagnetic field (200G). Results showed that the pulse electromagnetic field has a faster and better healing effect than the continuous magnetic field. The present study used a pulse magnetic field on pressure sores in the treatment group.

Aaron (19) studied the effects of the electromagnetic field in the stimulation of the regeneration of connective tissue, through the investigation of the healing of recent fractures and bone regeneration. Results showed that the magnetic field accelerates the extracellular matrix synthesis and tissue regeneration. Sauer (20) stated that magnetic field treatment in low frequencies had no impact on healing of $3^{\text {rd }}$ degree burn scars in rats.

Ottoni (21) studied the effects of a low frequency pulse electromagnetic field in rats, investigating the healing of the scar tissue under macroscopic and electron microscope. In the treatment group, there was a significant increase in scar contraction rate, in addition to the earlier development of cellular organization, collagen formation and development and vascularization. It can be argued that the same reasons account for the better healing of the pressure sores in the present study.

The present study applied the magnetic field treatment based on references of the BTL09 magnetotherapy devise, on a daily basis for 30 minutes and $15 \mathrm{mT}$ (150G). It evaluated the sizes of sore areas prior to the treatment $\left(1^{\text {st }}\right.$ day), on the $7^{\text {th }}$ day and the $15^{\text {th }}$ day, and observed a significant effect on the healing of the sore tissue.

The within group evaluations conducted prior to the treatment and the $7^{\text {th }}$ and $15^{\text {th }}$ days showed that both treatment methods were efficient and statistically significant. However, MF treatment yielded a shorter duration in healing wider scars. However, in order to determine the best protocol in the treatment of pressure sores, it is our belief that it would be beneficial to examine the sore tissue further and in more detail than the area of the tissue in order to provide more concrete results. In addition it is possible to set standards by making variations in the dose of the treatment.
The limitation of the study is the difference of scar area percentages between groups. In the treatment group, $80 \%$ of patients were stage at II but in the control group this percentage was $60 \%$.

In the light of the findings of this study, we believe that, with the use of MF in the treatment of pressure sores of stage II and III, the desired outcomes can be achieved in a shorter time. However, the prevention of pressure sores is always easier and less costly than their treatment. Therefore, the main concern should be the determination of the factors contributing to the development of pressure sores, and to provide the necessary training to health personnel.

\section{Conflict of Interest}

No conflict of interest was declared by the authors.

\section{References}

1. Maklebust J. Pressure ulcers: the great insult. Nurs Clin North Am 2005;40:365-89. [CrossRef]

2. Salcido R, Hard D, Smith AM. The prevention and Management of Pressure Ulcers. In: Braddom RL, editor. Physical Medicine \& Rehabilitation. WB saunders Company, Philadelphia USA;1996. p. 630-47. [CrossRef]

3. O'Connor KC, Kirshblum SC. Pressure ulcers. In: DeLisa JA, editor. Rehabilitataion Medicine. JB Lippincott, Phidelphia;1998. p. 1057-70.

4. Weintraub MI. Magnetotherapy: A new intervention? Arch Phys Med Rehabil 1998;79:469-70. [CrossRef]

5. Comorosan S, Vasilco R, Arghiropol M, Paslaru L, Jieanu V, Stelea $S$. The effect of diapulse therapy on the healing of decubitus ulcer. Rom J Physiol 1993;30:41-5.

6. Basset CA. Beneficial effects of electromagnetic fields-abstracts. J Cell Biochem 1993;51:387-93.

7. Navrátil L, Hlavatý V, Landsingerová E. Possible therapeutic applications of pulsed magnetic fields. Cas Lek Cesk 1993;132:590-4.

8. Itoh M, Montemayor JS Jr, Matsumoto E, Eason A, Lee MH, Folk FS. Accelerated wound healing of pressure ulcers by pulsed highpeak power electromagnetic energy (Diapulse). Decubitus 1991;4:29-34.

9. Alekseenko AV, Gusak W. Treatment of trophic ulcers of the lower extremities using a magnetic field. Klin Khir 1991;7:60-3.

10. Leaper DJ, Foster ME, Brennan SS, Davies PW. Do magnetic fields influence soft tissue wound healing? A preliminary communication-abstracts. EquineVet J 1985;17:178-80. [CrossRef]

11. Jones ML, Mathewson CS, Adkins VK, Ayllon T. Use of Behavioral contingencies to promote prevention of recurrent pressure ulcers. Arch Phys Med Rehabil 2003; 84: 796-802. [CrossRef]

12. John S, Mancoll and Linda G. Phillips Pressure Sores. In: Aston SJ, Bearley RW, Thorne CH, editors. Grabb and Smith's Plastic Surpery. Fifth Edition. Lippincott-Rayen Publishers, Phidelphia; 1997. p.1083-96.

13. Flemming K, Cullum N. Electromagnetic therapy for the treatment of pressure sores-abstracts. Cochrone Database Syst Rev 2001;CD002930.

14. Glassman LS, McGrath MH, Basset CA. Effect of external pulsing electromagnetic fields on the healing of soft tissue-abstracts. Ann Plast Surg 1986;16:287-95. [CrossRef]

15. Millgram J, Shahar R, Levin-Harrus T, Kass P. The effect of short, high intensity magnetic field pulses on the healing of skin wounds in rats-abstracts. J Vet Med Sci 1992;54:1017-22. 
16. Patino O, Grana D, Bolgiani A, Prezzavento G, Mino J, Merlo $A$, et al. Pulsed electromagnetic fields in experimental cutaneous wound healing in rats-abstracts. J Burn Care Rehabil 1996;17:528-31.

17. Lin Y, Nishimura R, Nazaki K, Sasaki N, Kodosava T, Goto N, Date $M$, Takeuchi A. Effects of pulsing electromagnetic fields on the ligament healing in rabbits-abstracts. Zhonggu Xiu Fu Chong Jian Wai Ke Za Zhi 1997;11:267-8.

18. Patino O, Grana D, Bolgiani A, Prezzavento G, Merlo A. Effect of magnetic fields on skin wound healing. Experimental studyabstracts. Medicina (B Aires) 1996;56:41-4.
19. Aaron RK, Ciombor DM. Therapeutic effects of electromagnetic fields in the stimulation of connective tissue repair-abstracts. J Cell Biochem 1993;52:42-6. [CrossRef]

20. Sauer HD, Rudy D. The significance of low-frequency magnetotherapy for local treatment of burns. An experimental comparative approach. Aktuelle Traumatol 1980;10:9-13.

21. Ottani V, De Pasquale V, Govoni P, Franchi M, Zaniol P, Ruggeri A. Effects of pulsed extremely-low frequency magnetic fields on skin wounds in rat-abstracts. Bioelectromagnetics 1988;9:53-62. [CrossRef] 